Research

Open Access

\title{
Cardiorespiratory effects of spontaneous breathing in two different models of experimental lung injury: a randomized controlled trial
}

\author{
Dirk Varelmann1, Thomas Muders' ${ }^{1}$, Jörg Zinserling1, Ulf Guenther ${ }^{1}$, Anders Magnusson², \\ Göran Hedenstierna ${ }^{3}$, Christian Putensen ${ }^{1}$ and Hermann Wrigge ${ }^{1}$
}

\author{
1Department of Anesthesiology and Intensive Care Medicine, University of Bonn, Sigmund-Freud-Strasse 25, D-53105 Bonn, Germany \\ 2Department of Radiology, University of Uppsala, University Hospital, SE-75185 Uppsala, Sweden \\ ${ }^{3}$ Department of Clinical Physiology, University of Uppsala, University Hospital, SE-75185 Uppsala, Sweden \\ Corresponding author: Hermann Wrigge, hermann.wrigge@ukb.uni-bonn.de
}

Received: 22 Jul 2008 Revisions requested: 29 Aug 2008 Revisions received: 3 Oct 2008 Accepted: 4 Nov 2008 Published: 4 Nov 2008

Critical Care 2008, 12:R135 (doi:10.1186/cc7108)

This article is online at: http://ccforum.com/content/12/6/R135

(c) 2008 Varelmann et al.; licensee BioMed Central Ltd.

This is an open access article distributed under the terms of the Creative Commons Attribution License (http://creativecommons.org/licenses/by/2.0), which permits unrestricted use, distribution, and reproduction in any medium, provided the original work is properly cited.

\begin{abstract}
Introduction Acute lung injury (ALI) can result from various insults to the pulmonary tissue. Experimental and clinical data suggest that spontaneous breathing (SB) during pressurecontrolled ventilation (PCV) in ALI results in better lung aeration and improved oxygenation. Our objective was to evaluate whether the addition of SB has different effects in two different models of ALI.
\end{abstract}

Methods Forty-four pigs were randomly assigned to ALI resulting either from hydrochloric acid aspiration ( $\mathrm{HCl}-\mathrm{ALI}$ ) or from increased intra-abdominal pressure plus intravenous oleic acid injections (OA-ALI) and were ventilated in PCV mode either with SB (PCV + SB) or without SB (PCV - SB). Cardiorespiratory variables were measured at baseline after induction of ALI and after 4 hours of treatment (PCV + SB or PCV - SB). Finally, density distributions and end-expiratory lung volume (EELV) were assessed by thoracic spiral computed tomography.

Results PCV + SB improved arterial partial pressure of oxygen/ inspiratory fraction of oxygen $\left(\mathrm{PaO}_{2} / \mathrm{FiO}_{2}\right)$ by a reduction in intrapulmonary shunt fraction in $\mathrm{HCl}-\mathrm{ALI}$ from $27 \% \pm 6 \%$ to $23 \% \pm 13 \%$ and in OA-ALI from $33 \% \pm 19 \%$ to $26 \% \pm 18 \%$, whereas during $\mathrm{PCV}-\mathrm{SB} \mathrm{PaO}_{2} / \mathrm{FiO}_{2}$ deteriorated and shunt fraction increased in the $\mathrm{HCl}$ group from $28 \% \pm 8 \%$ to $37 \% \pm$ $17 \%$ and in the OA group from $32 \% \pm 12 \%$ to $47 \% \pm 17 \%$ ( $P$ $<0.05$ for interaction time and treatment, but not ALI type). PCV $+\mathrm{SB}$ also resulted in higher EELV (HCl-ALI: $606 \pm 171 \mathrm{~mL}$, OAALI: $439 \pm 90 \mathrm{~mL}$ ) as compared with PCV - SB (HCl-ALI: 372 $\pm 130 \mathrm{~mL}$, OA-ALI: $192 \pm 51 \mathrm{~mL}$, with $P<0.05$ for interaction of time, treatment, and ALI type).

Conclusions SB improves oxygenation, reduces shunt fraction, and increases EELV in both models of ALI.

\footnotetext{
ALI: acute lung injury; APRV: airway pressure release ventilation; ARDS: acute respiratory distress syndrome; BL-ALI: baseline acute lung injury; CO: cardiac output; $\mathrm{CT}$ : computed tomography; CVP: central venous pressure; $\mathrm{DO}_{2}$ : oxygen delivery; $\mathrm{EELV}$ : end-expiratory lung volume; $\mathrm{FiO}_{2}$ : inspiratory fraction of oxygen; $\mathrm{HCl}$ : hydrochloric acid; $\mathrm{HCl}-\mathrm{ALI}$, hydrochloric acid-induced acute lung injury; HR: heart rate; IAP: intra-abdominal pressure; I/E: inspiratory/expiratory (ratio); ITBV: intrathoracic blood volume; MAP: mean arterial pressure; MIGET: multiple inert gas elimination technique; OA: oleic acid; OA-ALI, oleic acid-induced acute lung injury; $\mathrm{PaCO}_{2}$ : arterial partial pressure of carbon dioxide; $\mathrm{PaO}_{2}$ : arterial partial pressure of oxygen; $\mathrm{P}_{\mathrm{aw} \text {, mean }}$ : mean airway pressure; PCV: pressure-controlled ventilation; PEEP: positive end-expiratory pressure; $\mathrm{PEEP}_{\mathrm{I} \text {, dyn }}$ : dynamic intrinsic positive end-expiratory pressure; $P_{\text {es }}$ : esophageal pressure; $P_{\text {insp }}$ : inspiratory pressure; $P_{\text {transp, mean }}$ : mean transpulmonary airway pressure; ROI: region of interest; RR: respiratory rate; $\mathrm{SB}$ : spontaneous breathing; SD: standard deviation; $\mathrm{SD}_{\text {atelect }}$ : standard deviation of non-aerated tissue; $\mathrm{SD} \%$ atelect: fraction of non-aerated tissue per region of interest; SVR: systemic vascular resistance; $V_{A} /$ l: ventilation/perfusion (ratio); $V_{E}$ : minute ventilation; $\mathrm{VO}_{2}$ : oxygen consumption; $\mathrm{V}_{\mathrm{T}}$ : tidal volume.
} 


\section{Introduction}

Alveolar recruitment in response to therapeutic interventions such as mechanical ventilation with positive end-expiratory pressure (PEEP) has been suggested to differ between direct (pulmonary) or indirect (extrapulmonary) acute lung injury (ALI) or the acute respiratory distress syndrome (ARDS) [1-3]. In direct ALI/ARDS, the injury originates from the alveolar epithelium and is characterized by alveolar collapse, fibrinous exudates, and alveolar wall edema [4], which might result in an increased lung elastance while chest wall elastance is often normal Computed tomography (CT) scans show equal amounts of consolidation and ground-glass opacities, with consolidated areas favoring the vertebral regions [5]. In indirect ALI/ARDS, the insult originates from the vascular endothelium and may cause less damage to the lung but may be associated with increased chest wall elastance [6] often caused by restricted movements and cranial shift of the diaphragm due to increased intra-abdominal pressure (IAP) $[1,7]$. Ground-glass opacity predominates and is evenly distributed [5]. Thus, direct and indirect ALI/ARDS have been suggested to have two distinct diseases with different respiratory mechanics, histopathology, and CT findings $[1,5,8,9]$.

Maintaining unsupported spontaneous breathing (SB) with airway pressure release ventilation (APRV) has been shown to improve oxygenation when compared with controlled mechanical ventilation in patients with ALI/ARDS of different origin $[10,11]$. SB counteracts atelectasis formation and favors alveolar recruitment $[12,13]$, resulting in an improvement in ventilation/perfusion $\left(\dot{V}_{A} / \dot{Q}\right)$ matching [14-17]. On the other hand, during controlled ventilation, as the diaphragm relaxes, it is displaced by the weight of the contents of the abdominal cavity, leading to the redistribution of tidal volumes $\left(\mathrm{V}_{\mathrm{T}}\right)$ to anterior, non-dependent, and less perfused lung regions $[13,18]$. These effects may be even more pronounced in indirect ALI/ ARDS. Whether previously shown beneficial cardiopulmonary effects of SB might differ depending on ALI/ARDS origin has not been investigated yet. We asked the question of whether SB during pressure-controlled ventilation (PCV) improves oxygenation, $\dot{V}_{A} / \dot{Q}$ distribution, shunt fraction, and end-expiratory lung volume (EELV) in two different models of ALI. This research question was tested in porcine models of hydrochloric acid $(\mathrm{HCl})$-induced $\mathrm{ALI}$ and in the combination of oleic acid (OA) injection and elevated IAP.

\section{Materials and methods Animals}

Experiments were approved by the animal ethics committee of the University of Uppsala. Forty-four pigs were anesthetized and mechanically ventilated in the supine position. The animals of each group were further randomly assigned into subgroups receiving either $\mathrm{PCV}$ with $\mathrm{SB}(\mathrm{PCV}+\mathrm{SB})$ or without $\mathrm{SB}$ (PCV - SB). Anesthesia, tracheotomy, and fluid infusion were performed as previously described [12]. A detailed description of measurements and statistical analysis is provided in Additional data file 1.

\section{Ventilatory setting}

Pressure-controlled ventilation without spontaneous breathing

PCV is a time-cycled ventilatory mode applied at a respiratory rate $(R R)$ of 15 breaths per minute, an inspiratory to expiratory (I/E) ratio of $1: 1$, an inspiratory fraction of oxygen $\left(\mathrm{FiO}_{2}\right)$ of 0.5 , a PEEP of $5 \mathrm{~cm} \mathrm{H} \mathrm{H}_{2} \mathrm{O}$, and an inspiratory pressure $\left(\mathrm{P}_{\text {insp }}\right)$ resulting in a $V_{\mathrm{T}}$ of approximately $10 \mathrm{~mL} / \mathrm{kg}$ using a standard ventilator (Servo I; Siemens-Elema AB, Solna, Sweden) to maintain normocapnia (35 mm Hg $<$ arterial partial pressure of carbon dioxide $\left[\mathrm{PaCO}_{2}\right]<45 \mathrm{~mm} \mathrm{Hg}$ ). $\mathrm{P}_{\text {insp }}$ was adjusted accordingly. SB efforts were excluded by the absence of negative deflections in the esophageal pressure $\left(P_{\text {es }}\right)$ tracings. After induction of $A L I$ (baseline $A L I$ [BL-ALI]), RR had to be increased as well as $P_{\text {insp }}$ to compensate for a decrease of compliance and to maintain normocapnia. I/E, PEEP, and $\mathrm{FiO}_{2}$ were kept constant. After BL-ALI measurements, the animals were randomly assigned to continue controlled mechanical ventilation or to resume SB.

Pressure-controlled ventilation with spontaneous breathing Ventilator settings were guided by the principles described above. RR was decreased to 15 breaths per minute, which corresponds to approximately $50 \%$ of the RR after induction of $A L I$ (BL-ALI), for re-institution of SB (confirmed by animalgenerated inspiratory flow and concomitant negative $P_{\text {es }}$ deflections). I/E ratio was kept constant.

\section{Lung injury}

Hydrochloric acid-induced acute lung injury

$\mathrm{HCl}(0.1 \mathrm{M})$ was intratracheally instilled until a stable lung injury was achieved.

Oleic acid-induced acute lung injury

The abdominal pressure was increased to $20 \mathrm{~cm} \mathrm{H}_{2} \mathrm{O}$ by infusion of normal saline into the abdominal cavity, followed by central venous injection of $\mathrm{OA}$. We aimed at a target arterial partial pressure of oxygen $\left(\mathrm{PaO}_{2}\right) / \mathrm{FiO}_{2}$ of less than $200 \mathrm{~mm}$ $\mathrm{Hg}$, but a $\mathrm{PaO}_{2} / \mathrm{FiO}_{2}$ of less than $300 \mathrm{~mm} \mathrm{Hg}$ was accepted after stabilization of ALI.

\section{Measurements}

Instrumentation of the animals has been described previously [19]. Heart rate (HR) and intravascular pressures were measured using standard technology [19]. Cardiac output (CO) and intrathoracic blood volume (ITBV) were determined with the transpulmonary thermal-indicator dilution technique [19]. Systemic and pulmonary vascular resistances were calculated using standard equations. Gas flow and derived variables, as well as airway and $P_{\text {es }}$ values, were continuously determined and stored on personal computers for offline analyses. Blood gases were analyzed using standard blood gas electrodes, 
and oxygen saturation and hemoglobin were analyzed using spectrophotometry. $\dot{V}_{A} / \dot{Q}$ distribution was measured using the multiple inert gas elimination technique (MIGET) [20]. Spiral scans were performed at the end of the experiments for determination of density distributions and pulmonary air content, which should represent EELV. Scans were carried out in randomized directions at end-inspiration and end-expiration with the tube clamped, and images were stored on personal computers for offline analysis.

\section{Protocol}

An illustration of the study protocol is given in Figure 1. In brief, blood gases and hemodynamic and ventilatory parameters were obtained 30 minutes after completing instrumentation (Pre-ALI) and 60 minutes after completing initiation of $A L I$ (BL$A L I)$, together with the first MIGET measurement, and the animals were subjected to controlled mechanical ventilation without SB. Thereafter, animals of the two groups $(\mathrm{HCl}$-induced and $\mathrm{OA}$-induced $\mathrm{ALI}$ ) were further randomly assigned either to continue with controlled mechanical ventilation (PCV - SB) or to additional SB (PCV + SB). After 240 minutes, another set of measurements, including MIGET and CT scans, was performed (Treatment). The overall study period was 8 hours. Four animals died in the course of the experiments: two pigs died directly after induction of lung injury; in two others, for technical reasons, no CT scans were obtained, resulting in $n$ $=11$ in the $\mathrm{HCl}-\mathrm{ALI} \mathrm{PCV}+\mathrm{SB}$ group, $\mathrm{n}=11$ in the $\mathrm{HCl}-\mathrm{ALI}$ PCV - SB group, $n=8$ in the OA-ALI PCV + SB group, and $\mathrm{n}=10$ in the OA-ALI PCV - SB group.

\section{Statistical analysis}

To detect differences in $\mathrm{PaO}_{2} / \mathrm{FiO}_{2}$, shunt fraction, EELV, and amount of non-aerated lung between the ventilatory setting and lung injury groups with the given parallel design at a significance level of $5 \%(\alpha=0.05)$ with a probability of $80 \%$ ( $\beta=$ 0.20 ) based on an estimated difference of 0.62 of the mean standard deviation (SD) of the parameter, the number of animals to be studied is at least 40 . Results are expressed as mean $\pm S D$, and all analyses were performed using a statistical software package (Statistica for Windows 6.0; StatSoft, Inc., Tulsa, OK, USA). Data were tested for normal distribution by the Shapiro-Wilks W test and analyzed by a two-way analysis of variance for repeated measurements with factors 'mode' and 'time'. When a significant $F$ ratio was obtained, differences between the means were isolated for the specific factor (and for all factors in case of significant interaction) with the post hoc Tukey multiple comparison test. Differences were considered to be statistically significant for $P$ values of less than 0.05 .

\section{Results Lung injury}

Induction of $\mathrm{ALI}$ led to a comparable and severe hypoxemia with $\mathrm{PaO}_{2} / \mathrm{FiO}_{2}$ below $200 \mathrm{~mm} \mathrm{Hg}$ in 38 out of 40 animals in both $\mathrm{HCl}-\mathrm{ALI}$ and OA-ALI (Table S1 in Additional data file 1). As expected by the study design, in the $\mathrm{HCl}$ group, respiratory system compliance was decreased mainly by decreased lung compliance, and, in OA-ALI, due to decreased chest wall compliance associated with increased abdominal pressure (Table 1). Thus, in $\mathrm{HCl}-\mathrm{ALI}$, mean transpulmonary airway pressure $\left(\mathrm{P}_{\text {transp, mean }}\right)$ was higher at all times after induction of $\mathrm{ALI}(P<$ 0.05), and the dynamic intrinsic PEEP (PEEP $\left.{ }_{l, \text { dyn }}\right)$ was not influenced by the type of injury (Table 1 ). In both models, RR and airway pressures (Table 1) had to be increased to maintain alveolar ventilation (minute ventilation $\left[\mathrm{V}_{\mathrm{E}}\right]$ ) after $A L I$ induction. In the OA group, EELV and longitudinal lung dimensions (distances of apex - dome and apex - costodiaphragmatic recessus) were significantly smaller than in the $\mathrm{HCl}$ group $(P$ $<0.05$, Table S4 in Additional data file 1). In HCl-ALI, shunt decreased after 4 hours of treatment $(P<0.05$, Table 2$)$, whereas dead space ventilation $\left(\dot{V}_{A} / \dot{Q} \rightarrow \infty\right)$ increased irrespective of $\mathrm{ALI}$ type and ventilatory mode $(P<0.05$, effect time).

For both types of ALI, the CT scans showed a gravity-dependent distribution of non-aerated tissue, predominantly in the dorsal areas $(P<0.05)$, and the aerated tissue found in the ventral parts of the lung $(P<0.05)$ (Figure 2$)$. This effect is more pronounced in the juxtadiaphragmatic lung regions $(P<$ $0.05)$ compared with the apical parts of the lung and is not dependent on the ALI type. The shunt fraction determined with the MIGET correlates with the amount of non-aerated lung tissue observed in the spiral CT scans (HCl-ALI: $y=0.85 x-$ $0.02, R^{2}=0.58$; OA-ALI: $\left.\mathrm{y}=1.19 \mathrm{x}-0.03, R^{2}=0.84\right)$. In $\mathrm{HCl}-$ generated ALI, however, the amount of non-aerated tissue is increased in the right region of interest (ROI) $(P<0.05)$, whereas an increase in aeration is found in the left ROI $(P<$ $0.05)$. The $S D$ of non-aerated tissue $\left(S D_{\text {atelect }}\right)$ and the fraction of non-aerated tissue per ROI (SD\% $\left.{ }_{\text {atelect }}\right)$ over all slices of the spiral scans did not differ between the two models of $A L I$ $\left(\mathrm{SD}_{\text {atelect }}: 4.3\right.$ versus $3.9 ; \mathrm{SD} \%_{\text {atelect }}: 0.13$ versus 0.13 , for $\mathrm{HCl}$-induced versus $\mathrm{OA}$-induced ALI).

\section{Pressure-controlled ventilation without spontaneous breathing}

In $\mathrm{PCV}-\mathrm{SB}, \mathrm{PaO}_{2} / \mathrm{FiO}_{2}$ deteriorated significantly $(P<0.05$ for interaction of time and ventilatory mode) (Table 2). CT scans showed a greater fraction of non-aerated tissue in this group $(P<0.05$, Figure 2$)$. $\mathrm{V}_{\mathrm{T}}$ decreased slightly as compared with baseline ALI $(P<0.05)$, whereas $\mathrm{PaCO}_{2}$ increased $(P<$ $0.05)$ despite higher mean airway $\left(P_{\text {aw, mean }}\right)$ and transpulmonary $\left(P_{\text {transp, mean }}\right)$ pressures $(P<0.05)$ (Table 1$) . \mathrm{CO}$ increased during the 4-hour treatment period in this group $(P$ $<0.05$ ) (Table 2), and a marked increase in blood flow to shunt regions $\left(\dot{V}_{A} / \dot{Q}=0\right)(P<0.05$, Table 2$)$ with a reduction in blood flow to regions with a normal $\dot{V}_{A} / \dot{Q}\left(0.1<\dot{V}_{A} / \dot{Q}<\right.$ 10) was observed (Figure 3). 


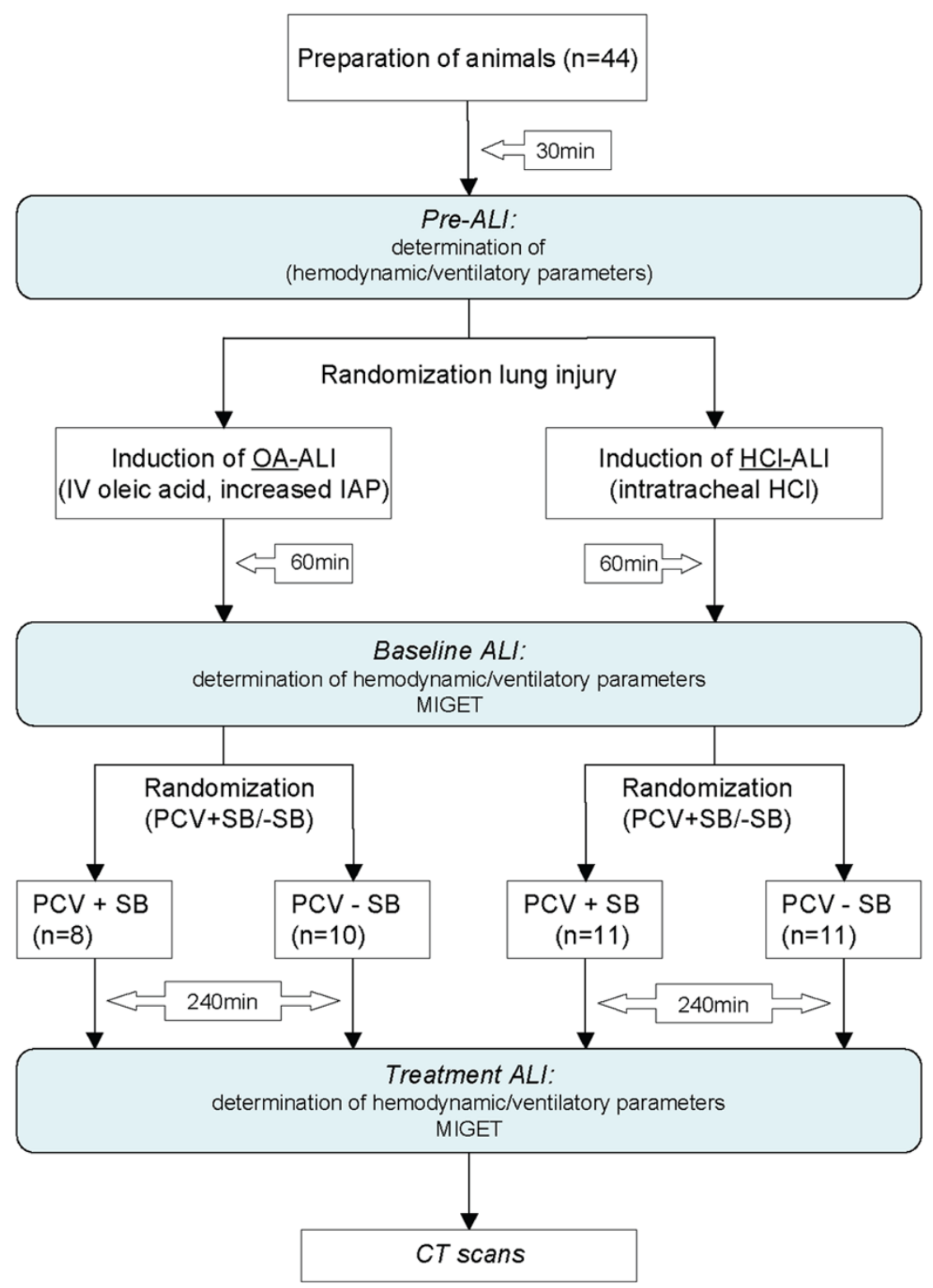

Flowchart of the study protocol. The grey boxes represent the measurement points. ALI, acute lung injury; $\mathrm{CT}$, computed tomography; $\mathrm{HCl}$, hydrochloric acid; $\mathrm{HCl}-\mathrm{ALI}$, hydrochloric acid-induced acute lung injury; IAP, intra-abdominal pressure; IV, intravenous; MIGET, multiple inert gas elimination technique; OA-ALI, oleic acid-induced acute lung injury (combined with an increased intra-abdominal pressure); PCV + SB, pressure-controlled ventilation with spontaneous breathing; PCV - SB, pressure-controlled ventilation without spontaneous breathing.

\section{Pressure-controlled ventilation with spontaneous breathing}

$\mathrm{PCV}+\mathrm{SB}$ improved $\mathrm{PaO}_{2} / \mathrm{FiO}_{2}$ during 4 hours of treatment $(P$ $<0.05$, interaction time course and ventilatory mode, Table 2$)$. Overall lung density was lower compared with PCV - SB $(P<$ $0.05)$; accordingly, the fraction of normally aerated tissue was higher in the PCV + SB group $(P<0.05)$ (Figure 4). The EELV and longitudinal lung dimensions were greater during SB compared with the PCV - SB group $(P<0.05)$. These effects were independent of the ALI type, with EELV and longitudinal dimensions always greater in $\mathrm{HCl}-\mathrm{ALI}$. SB led to an increase in RR $(P<0.05)$ with a concomitant decrease in VT $(P<0.05)$ and increases in $\mathrm{V}_{\mathrm{E}}$ and $\mathrm{PaCO}_{2}$. The increase in $\mathrm{PaCO}_{2}$, however, was lower as compared with PCV - SB $(P<0.05$, Table 1). The $V_{T}$ of spontaneous breaths was lower in the OA-ALI group. The increases in $\mathrm{P}_{\text {aw, mean }}$ and $\mathrm{P}_{\text {transp, mean }}(P<0.05)$ were comparable with the increases in the PCV - SB group, PEEP was comparable in the two groups, and PEEP $P_{I \text {, dyn }}$ was not significantly different between the two groups and was less than $1 \mathrm{~cm} \mathrm{H}_{2} \mathrm{O}$. Blood flow to low $\dot{V}_{A} / \dot{Q}$ compartments 
Table 1

\begin{tabular}{|c|c|c|c|c|c|c|c|c|c|}
\hline & & SB & Baseline ALI & Treatment & Lung injury & Time & Injury type & Mode & Inter-action \\
\hline \multirow[t]{4}{*}{$\mathrm{RR}$, breaths per minute } & $\mathrm{HCl}$ & + & $28.2 \pm 3.4$ & $45.3 \pm 8.5^{b}$ & a & a & & a & \\
\hline & & - & $28.4 \pm 2.8$ & $28.3 \pm 3.2^{c}$ & & & & & \\
\hline & OA & + & $29.2 \pm 0.1$ & $43.5 \pm 6.7^{b}$ & & & & & \\
\hline & & - & $29.1 \pm 1.8$ & $29.2 \pm 1.7^{c}$ & & & & & \\
\hline \multirow[t]{4}{*}{$\mathrm{V}_{\mathrm{T}}, \mathrm{mL}$} & $\mathrm{HCl}$ & + & $326 \pm 46$ & $212 \pm 28^{b}$ & & & & & \\
\hline & & - & $303 \pm 23$ & $272 \pm 20^{b}$ & a & a & & a & $\mathrm{TM}^{\mathrm{a}}$ \\
\hline & OA & + & $317 \pm 41$ & $190 \pm 19 b$ & & & & & \\
\hline & & - & $285 \pm 52$ & $260 \pm 31^{b}$ & & & & & \\
\hline \multirow[t]{4}{*}{$\mathrm{V}_{\mathrm{T}, \mathrm{sb}}, \mathrm{mL}$} & $\mathrm{HCl}$ & + & $\mathrm{n} / \mathrm{a}$ & $135 \pm 20$ & & & a & & \\
\hline & & - & $\mathrm{n} / \mathrm{a}$ & $\mathrm{n} / \mathrm{a}$ & & & & & \\
\hline & OA & + & $\mathrm{n} / \mathrm{a}$ & $95 \pm 19^{d}$ & & & & & \\
\hline & & - & $\mathrm{n} / \mathrm{a}$ & $\mathrm{n} / \mathrm{a}$ & & & & & \\
\hline \multirow[t]{4}{*}{$\mathrm{V}_{\mathrm{E}}$, liters } & $\mathrm{HCl}$ & + & $8.8 \pm 1.1$ & $8.6 \pm 1.5$ & a & a & & a & \\
\hline & & - & $8.5 \pm 0.9^{c}$ & $7.6 \pm 1.1^{\mathrm{c}}$ & & & & & \\
\hline & OA & + & $9.1 \pm 1.2$ & $7.7 \pm 1.2$ & & & & & \\
\hline & & - & $8.0 \pm 1.0^{c}$ & $7.4 \pm 0.6^{c}$ & & & & & \\
\hline \multirow[t]{4}{*}{$\mathrm{PaCO}_{2}, \mathrm{~mm} \mathrm{Hg}$} & $\mathrm{HCl}$ & + & $40 \pm 6$ & $45 \pm 9$ & a & a & & a & $\mathrm{TM}^{\mathrm{a}}$ \\
\hline & & - & $42 \pm 9$ & $54 \pm 13^{c}$ & & & & & \\
\hline & OA & + & $41 \pm 9$ & $43 \pm 10$ & & & & & \\
\hline & & - & $46 \pm 10$ & $54 \pm 17 c$ & & & & & \\
\hline \multirow[t]{4}{*}{$P_{\text {transp, mean }}$, mbar } & $\mathrm{HCl}$ & + & $5.5 \pm 3.0$ & $5.5 \pm 4.6$ & a & a & a & & \\
\hline & & - & $6.8 \pm 3.3$ & $8.1 \pm 3.4$ & & & & & \\
\hline & OA & + & $2.1 \pm 3.0$ & $2.7 \pm 3.4$ & & & & & \\
\hline & & - & $0.5 \pm 3.2$ & $3.1 \pm 3.5$ & & & & & \\
\hline \multirow[t]{4}{*}{$\mathrm{PEEP}_{\mathrm{I}, \mathrm{dyn}}$, mbar } & $\mathrm{HCl}$ & + & $0.0 \pm 1.1$ & $0.3 \pm 0.3$ & & & & & \\
\hline & & - & $0.7 \pm 0.6$ & $0.9 \pm 0.9$ & & & & & \\
\hline & OA & + & $0.0 \pm 1.6$ & $0.8 \pm 0.5$ & & & & & \\
\hline & & - & $0.3 \pm 0.3$ & $0.0 \pm 1.6$ & & & & & \\
\hline \multirow[t]{4}{*}{$\mathrm{C}_{\mathrm{cw}}, \mathrm{mL} / \mathrm{mbar}$} & $\mathrm{HCl}$ & + & $89.3 \pm 39.3$ & $\mathrm{n} / \mathrm{a}$ & & & a & & \\
\hline & & - & $96.8 \pm 34.9$ & $115.5 \pm 64.3$ & & & & & \\
\hline & $\mathrm{OA}$ & + & $40.9 \pm 14.8^{d}$ & $\mathrm{n} / \mathrm{a}$ & & & & & \\
\hline & & - & $39.3 \pm 11.2^{d}$ & $49.5 \pm 27.6^{d}$ & & & & & \\
\hline \multirow[t]{4}{*}{$\mathrm{C}_{\text {lung }}, \mathrm{mL} / \mathrm{mbar}$} & $\mathrm{HCl}$ & + & $19.5 \pm 4.0$ & $\mathrm{n} / \mathrm{a}$ & a & & a & & \\
\hline & & - & $16.4 \pm 8.4$ & $13.5 \pm 2.8$ & & & & & \\
\hline & OA & + & $21.3 \pm 4.7^{d}$ & $\mathrm{n} / \mathrm{a}$ & & & & & \\
\hline & & - & $21.7 \pm 8.3^{d}$ & $16.2 \pm 7.9^{d}$ & & & & & \\
\hline \multirow[t]{2}{*}{$\mathrm{R}, \mathrm{mbar} / \mathrm{L}$ per second } & $\mathrm{HCl}$ & + & $7.0 \pm 0.7^{b}$ & $\mathrm{n} / \mathrm{a}$ & & & a & a & \\
\hline & & - & $7.5 \pm 1.6^{b}$ & $8.5 \pm 2.8$ & & & & & \\
\hline
\end{tabular}


Table 1 (Continued)

Ventilation and respiratory system mechanics

\begin{tabular}{|c|c|c|c|c|c|c|}
\hline & $\mathrm{OA}$ & + & $8.5 \pm 1.0^{b}$ & $\mathrm{n} / \mathrm{a}$ & & \\
\hline & & - & $9.0 \pm 3.0^{b}$ & $11.9 \pm 2.7$ & & \\
\hline \multirow[t]{4}{*}{ EELV, mL } & $\mathrm{HCl}$ & + & & $606 \pm 171$ & a & a \\
\hline & & - & & $372 \pm 130^{\circ}$ & & \\
\hline & OA & + & & $439 \pm 90^{d}$ & & \\
\hline & & - & & $192 \pm 51^{c, d}$ & & \\
\hline
\end{tabular}

Pre-acute lung injury (ALI) (Table S2 in additional data file 1) was tested only against baseline ALI. Post hoc testing was always performed if a significant $\mathrm{F}$ ratio for a factor or the interaction of factors was obtained by repeated measures analysis of variance (aP< $<.05)$, but only significant differences are marked: ${ }^{b} P<0.05$ for within-group differences (ALI versus Treatment), ${ }^{c} P<0.05$ for between-group differences (PCV + SB versus PCV - SB), and d $P<0.05$ for between-group differences (HCl-ALI versus OA-ALI) (post hoc Tukey multiple comparison test). +, pressurecontrolled ventilation with maintained spontaneous breathing; -, pressure-controlled ventilation without spontaneous breathing; $\mathrm{C}_{\mathrm{C}}$, chest wall compliance; $\mathrm{C}_{\text {lung }}$, lung compliance; $\mathrm{EELV}$, end-expiratory lung volume; $\mathrm{HCl}$, hydrochloric acid-induced acute lung injury; $\mathrm{M}$, mode; $\mathrm{n} / \mathrm{a}$, not applicable; $\mathrm{OA}$, oleic acid-induced acute lung injury; $\mathrm{PaCO}_{2}$, arterial partial pressure of carbon dioxide; $\mathrm{PCV}+\mathrm{SB}$, pressure-controlled ventilation with spontaneous breathing; PCV - SB, pressure-controlled ventilation without spontaneous breathing; $P E E P_{1}$, dynamic intrinsic positive endexpiratory pressure; $P_{\text {transp mean }}$, mean transpulmonary airway pressure; $R$, respiratory system resistance; $R R$, respiratory rate; $S B$, spontaneous breathing; $T$, time; $V_{\mathrm{E}}$, minute ventilation; $\mathrm{V}_{\mathrm{T}}$, tidal volume; $\mathrm{V}_{\mathrm{T}, \mathrm{sb}}$, tidal volume of spontaneous breaths.

$\left(0.005<V_{A} / Q<0.1\right)$ increased during $\mathrm{PCV}+\mathrm{SB}$ in the $\mathrm{HCl}$ group only $(P<0.001$, Table S5 in Additional data file 1). In both groups, PCV - SB and PCV + SB, the HR and mean arterial pressure (MAP) increased during the 4-hour treatment period $(P<0.05)$, whereas central venous pressure (CVP) and systemic vascular resistance (SVR) dropped $(P<0.05$, Table 2), and pulmonary artery occlusion pressure (PAOP) and ITBV remained unchanged (Table S3 in Additional data file 1).

\section{Discussion}

Our data confirm previous findings that SB during PCV leads to an improvement in oxygenation through the reduction in shunt and restoration of aeration in previously non-aerated lung regions. These effects are not influenced by the type of ALI/ARDS studied here.

\section{Lung injury}

Although one should be careful in drawing conclusions from findings in animal models for treatment of patients with ARDS, our different lung injury types mimic relevant aspects of the clinical situation. $\mathrm{HCl}$ aspiration damaged the alveolar epithelium and increased lung elastance usually due to alveolar flooding and collapse, reduced removal of edema fluid, and reduced production of surfactant [4,21-23]. Commonly, $\mathrm{HCl}$ induced $A L I$ is regarded as a form of direct ALI. OA injection combined with abdominal hypertension [1] causes damage to the vascular endothelium, resulting in increased chest wall elastance usually associated with microvascular congestion, interstitial edema, and recruitment of inflammatory cells, whereas the intra-alveolar spaces are spared [24], mimicking indirect ALI. Although OA exhibits direct toxicity to endothelial cells [25], the elicited lung injury might not be similar to ALI caused by sepsis. However, OA generates a reproducible injury within a reasonable time frame.
According to our knowledge, the differences of direct and indirect ALI/ARDS have been described qualitatively only, revealing a heterogeneous distribution pattern (for example, 'patchy pattern') of normal lung, regions with ground-glass opacity, and consolidated areas. In the current literature, different distribution patterns of inhomogeneities are described $[2,5,26,27]$. We attempted to quantify the heterogeneities by determining the SD of density distributions in eight ROls per transverse slide assessed with spiral CT scans. However, this approach did not reveal any quantitative differences and the authors were not able to distinguish the type of injury by visual inspection in a significant number of animals. This suggests either that there are no morphological differences between these models of $\mathrm{ALI}$ or that the differences are too small to be detected with the used CT technique. Desai and colleagues [8] were not able to describe a single CT feature to predict whether ARDS in humans is of direct or indirect origin. These findings suggest that both injury types result in interstitial pulmonary edema as a common final path. The greater amount of injury in the right lungs in $\mathrm{HCl}$-induced $\mathrm{ALI}$ is well known from aspiration pneumonia.

The additional fluid volume infused into the abdominal cavity in the OA group influences hemodynamic parameters; MAP was higher in the OA group ( $P<0.05$, effect injury type) as an effect of an increased SVR $(P<0.05$, effect injury type; Table $2)$, and $C O$ was not different between the injury models. However, the ITBV was not significantly different between OAinduced and $\mathrm{HCl}$-induced ALI (Table W3 in Additional data file 1 ), and on average very little normal saline had to be replaced for maintaining IAP $(<100 \mathrm{~mL}$ ), thus effects other than intravascular shifting of intraperitoneal fluid might account for this.

The rationale to investigate the effects of SB in two different $A L I$ models was that they might differ in their potential for recruitment $[1,28,29]$. Recruitment maneuvers differ in their 
Table 2

\begin{tabular}{|c|c|c|c|c|c|c|c|c|c|}
\hline & & SB & BL-ALI & Treatment & Lung injury & Time & Injury type & Mode & Inter-action \\
\hline \multirow[t]{4}{*}{$\mathrm{PaO}_{2} / \mathrm{FiO}_{2}, \mathrm{~mm} \mathrm{Hg}$} & $\mathrm{HCl}$ & + & $132 \pm 18$ & $150 \pm 50$ & a & & & & $\mathrm{TM}^{\mathrm{a}}$ \\
\hline & & - & $151 \pm 58$ & $137 \pm 104$ & & & & & \\
\hline & OA & + & $145 \pm 51$ & $184 \pm 116$ & & & & & \\
\hline & & - & $146 \pm 68$ & $109 \pm 46$ & & & & & \\
\hline \multirow[t]{4}{*}{$\mathrm{HR}$, beats per minute } & $\mathrm{HCl}$ & + & $96 \pm 12$ & $112 \pm 11$ & a & a & & & \\
\hline & & - & $100 \pm 22$ & $108 \pm 20$ & & & & & \\
\hline & OA & + & $102 \pm 11$ & $110 \pm 23$ & & & & & \\
\hline & & - & $112 \pm 18$ & $119 \pm 23$ & & & & & \\
\hline \multirow[t]{4}{*}{$\mathrm{MAP}, \mathrm{mm} \mathrm{Hg}$} & $\mathrm{HCl}$ & + & $79 \pm 8$ & $86 \pm 9^{b}$ & & a & a & & \\
\hline & & - & $77 \pm 23$ & $92 \pm 13^{b}$ & & & & & \\
\hline & OA & + & $93 \pm 12^{d}$ & $97 \pm 13^{b, d}$ & & & & & \\
\hline & & - & $101 \pm 10^{d}$ & $104 \pm 15^{b, d}$ & & & & & \\
\hline \multirow[t]{4}{*}{$\mathrm{CVP}, \mathrm{mm} \mathrm{Hg}$} & $\mathrm{HCl}$ & + & $11 \pm 2$ & $10 \pm 2^{b}$ & a & & & & \\
\hline & & - & $12 \pm 3$ & $12 \pm 2^{b}$ & & & & & \\
\hline & OA & + & $15 \pm 2^{d}$ & $14 \pm 2^{b, d}$ & & & & & \\
\hline & & - & $15 \pm 4^{d}$ & $14 \pm 3^{b, d}$ & & & & & \\
\hline \multirow[t]{4}{*}{ SVR, dyne-second/cm 5} & $\mathrm{HCl}$ & + & $1,335 \pm 198$ & $1,057 \pm 191^{b}$ & a & a & a & & \\
\hline & & - & $1,255 \pm 429$ & $1,072 \pm 333^{b}$ & & & & & \\
\hline & OA & + & $1,513 \pm 344$ & $1,281 \pm 388^{b}$ & & & & & \\
\hline & & - & $1,490 \pm 384$ & $1,060 \pm 206^{b}$ & & & & & \\
\hline \multirow[t]{4}{*}{$\mathrm{CO}, \mathrm{L} /$ minute } & $\mathrm{HCl}$ & + & $4.1 \pm 0.3$ & $4.6 \pm 0.8$ & a & & & a & \\
\hline & & - & $4.2 \pm 0.9^{c}$ & $4.8 \pm 0.9^{c}$ & & & & & \\
\hline & OA & + & $4.2 \pm 0.7$ & $4.3 \pm 0.8$ & & & & & \\
\hline & & - & $4.8 \pm 0.8^{c}$ & $5.5 \pm 0.7^{c}$ & & & & & \\
\hline \multirow[t]{4}{*}{$\mathrm{DO}_{2}, \mathrm{~mL} /$ minute } & $\mathrm{HCl}$ & + & $323 \pm 28$ & $393 \pm 71$ & a & a & & & \\
\hline & & - & $336 \pm 63$ & $369 \pm 89$ & & & & & \\
\hline & OA & + & $335 \pm 89$ & $360 \pm 48$ & & & & & \\
\hline & & - & $408 \pm 80$ & $430 \pm 118$ & & & & & \\
\hline \multirow[t]{4}{*}{$\mathrm{VO}_{2}, \mathrm{~mL} /$ minute } & $\mathrm{HCl}$ & + & $181 \pm 31$ & $172 \pm 33$ & a & & a & & \\
\hline & & - & $169 \pm 23$ & $172 \pm 32$ & & & & & \\
\hline & OA & + & $159 \pm 27^{c}$ & $147 \pm 34^{c}$ & & & & & \\
\hline & & - & $154 \pm 32^{c}$ & $167 \pm 42^{c}$ & & & & & \\
\hline \multirow[t]{4}{*}{ Shunt $\dot{V}_{A} / \dot{Q}<0.005, \% \mathrm{Q}_{\mathrm{T}}$} & $\mathrm{HCl}$ & + & $27.1 \pm 6.2$ & $23.3 \pm 12.7$ & & a & & & $\mathrm{TM}^{\mathrm{a}}$ \\
\hline & & - & $27.7 \pm 7.9$ & $37.4 \pm 17.4^{b}$ & & & & & \\
\hline & OA & + & $32.6 \pm 18.9$ & $26.0 \pm 17.9$ & & & & & \\
\hline & & - & $32.4 \pm 12.4$ & $47.2 \pm 17.1^{b}$ & & & & & \\
\hline Dead space $\dot{V}_{A} / \dot{Q}>100, \% \mathrm{Ve}$ & $\mathrm{HCl}$ & + & $33.0 \pm 5.5$ & $45.1 \pm 11.8$ & & a & & & \\
\hline
\end{tabular}




$$
\begin{array}{rrrr} 
& - & 34.4 \pm 5.9 & 38.7 \pm 3.9 \\
\mathrm{OA}+ & 39.1 \pm 6.6 & 44.9 \pm 12.8 \\
& - & 39.0 \pm 6.0 & 46.2 \pm 12.2
\end{array}
$$

Pre-acute lung injury (ALI) (Table S1 in additional data file) was tested only against baseline ALI (BL-ALI). Post hoc testing was always performed if a significant $\mathrm{F}$ ratio for a factor or the interaction of factors was obtained by repeated measures analysis of variance $(a P<0.05)$, but only significant differences are marked: ${ }^{b} P<0.05$ for within-group differences (BL-ALI versus Treatment), $c P<0.05$ for between-group differences ( $\mathrm{HCl}$-ALI versus OA-ALI), and $\mathrm{d} P<0.05$ for between-group differences (PCV + SB versus PCV - SB) (post hoc Tukey multiple comparison test). + , pressure-controlled ventilation with maintained spontaneous breathing; -, pressure-controlled ventilation without spontaneous breathing; CO, cardiac output; CVP, central venous pressure; $\mathrm{DO}_{2}$, oxygen delivery; $\mathrm{HCl}$, hydrochloric acid-induced acute lung injury; $\mathrm{HCl}-\mathrm{ALI}$, hydrochloric acidinduced acute lung injury; HR, heart rate; M, mode; MAP, mean arterial pressure; OA, oleic acid-induced acute lung injury; OA-ALI, oleic acidinduced acute lung injury; $\mathrm{PaO}_{2} / \mathrm{FiO}_{2}$, arterial partial pressure of oxygen/inspiratory fraction of oxygen; $\mathrm{PCV}+\mathrm{SB}$, pressure-controlled ventilation with spontaneous breathing; PCV - SB, pressure-controlled ventilation without spontaneous breathing; \% $\mathrm{Q}_{\mathrm{T}}$, percentage of cardiac output; SB,

spontaneous breathing; SVR, systemic vascular resistance; T, time; $\dot{V}_{A} / \dot{Q}$, ventilation/perfusion (ratio); \%Ve, percentage of minute ventilation; $\mathrm{VO}_{2}$, oxygen consumption.

effect on oxygenation and lung mechanics in an animal model of intratracheal and intraperitoneal lipopolysaccharide injections, with recruitment maneuvers being more effective in animals with intraperitoneally injected lipopolysaccharide [29]. Recent data, however, challenged this concept: a multicenter CT study in 68 patients with ALI or ARDS was unable to detect any difference in alveolar recruitment potential depending on the type of $\mathrm{ALI}$, but huge individual differences were detected [30]. A recent study found the volume recruited by different levels of PEEP (10 and $14 \mathrm{~cm} \mathrm{H}_{2} \mathrm{O}$ ) in patients with direct and indirect ARDS to be similar, but classification of ARDS was uncertain in more than one third (37\%) of patients [31]. The PEEP used in this study was considerably low and might not have prevented atelectasis formation. The aim of this study, however, was to study the effects of SB in different ALI models and not the effects of other recruitment strategies such as recruitment maneuvers or high PEEP. Intrinsic PEEP was below $1 \mathrm{~cm} \mathrm{H}_{2} \mathrm{O}$ in all situations and therefore was not considered clinically significant. The meta-analysis of studies did not find any differences in outcome in patients with direct or indirect ALI/ARDS [32]. These recent findings suggest that differences in alveolar recruitment potential are attributable to individual differences between patients rather than to the systematic origin of ALI/ARDS. This is in line with our experimental findings that beneficial effects of SB on lung recruitment do not depend on the origin of ALI/ARDS.

\section{Effects of spontaneous breathing on respiratory variables}

$\mathrm{PCV}+\mathrm{SB}$ resulted in a higher EELV, greater lung dimensions, and less non-aerated tissue (Figure 4), indicating that SB prevents a loss of aeration. During SB, the posterior muscular sections of the diaphragm move more than the anterior tendon plate [17] and ventilation is shifted to the dependent lung regions [33], thereby counteracting atelectasis formation and resulting in improvement in $\dot{V}_{A} / \dot{Q}$ matching $[14,16]$. The finding that EELV was lower in OA-induced ALI can be explained by the elevated IAP and, as a consequence, a cranial displace- ment of the diaphragm with compression atelectasis or consolidation of the juxtadiaphramatic lung regions [34,35].

$\mathrm{V}_{\mathrm{T}}$ tended to be smaller when SB was maintained. This is a consequence of the unsupported spontaneous breaths, which occurred on the lower pressure level only. The spontaneous $V_{T}$ $\left(\mathrm{V}_{\mathrm{Tsb}}\right)$ was lower in the OA group due to the more cranially displaced diaphragm compared with the $\mathrm{HCl}$ group. As spontaneous breaths coincided with mechanical breaths delivered by the ventilator, it is difficult to determine the $V_{T}$ solely generated by ventilator. With the high spontaneous RR on the lower pressure level, plausible 'ventilator $\mathrm{V}_{\mathrm{T}}$ ' could not be calculated.

The good correlation of the shunt fraction determined with the MIGET with the amount of non-aerated lung tissue observed in the spiral CT scans has already been shown by others [5]. This suggests that loss of aeration (also indicated by the reduction in EELV) was the main reason for the shunt fraction and that the prevention of this loss of aeration in these lung areas by SB contributed to the improvement in oxygenation, regardless of ALI type. This is in agreement with previous studies reporting a reduction in intrapulmonary shunting in PCV with SB $[10,12,16,36,37]$. Intrapulmonary shunt in ARDS/ALI has been found to correlate directly with the quantity of nonaerated tissue in dependent lung regions [5,14,38]. In $\mathrm{HCl}$ induced $A L I$ with maintained $S B$, the blood flow to low $\dot{V}_{A} / \dot{Q}$ $\left(0.005<\dot{V}_{A} / \dot{Q}<0.1\right)$ was significantly higher than in $\mathrm{HCl}-\mathrm{ALI}$ without $\mathrm{SB}$ and in $\mathrm{OA}-\mathrm{ALI}$ with and without $\mathrm{SB}$. $\mathrm{HCl}$ instillation led to alveolar flooding and collapse, and the physiologic response is to divert blood flow away from non-ventilated regions (hypoxic pulmonary vasoconstriction). PCV + SB in $\mathrm{HCl}$-induced $\mathrm{ALI}$ might have restored ventilation in those regions and might have led to an increase in perfused low $\dot{V}_{A} / \dot{Q}$ areas that participate in gas exchange. The effects of low $\dot{V}_{A} / \dot{Q}$ on blood oxygenation, however, will depend on $\mathrm{FiO}_{2}$. With low $\mathrm{FiO}_{2}$, low $\dot{V}_{A} / \dot{Q}$ regions contribute to impaired 
Non-aerated tissue

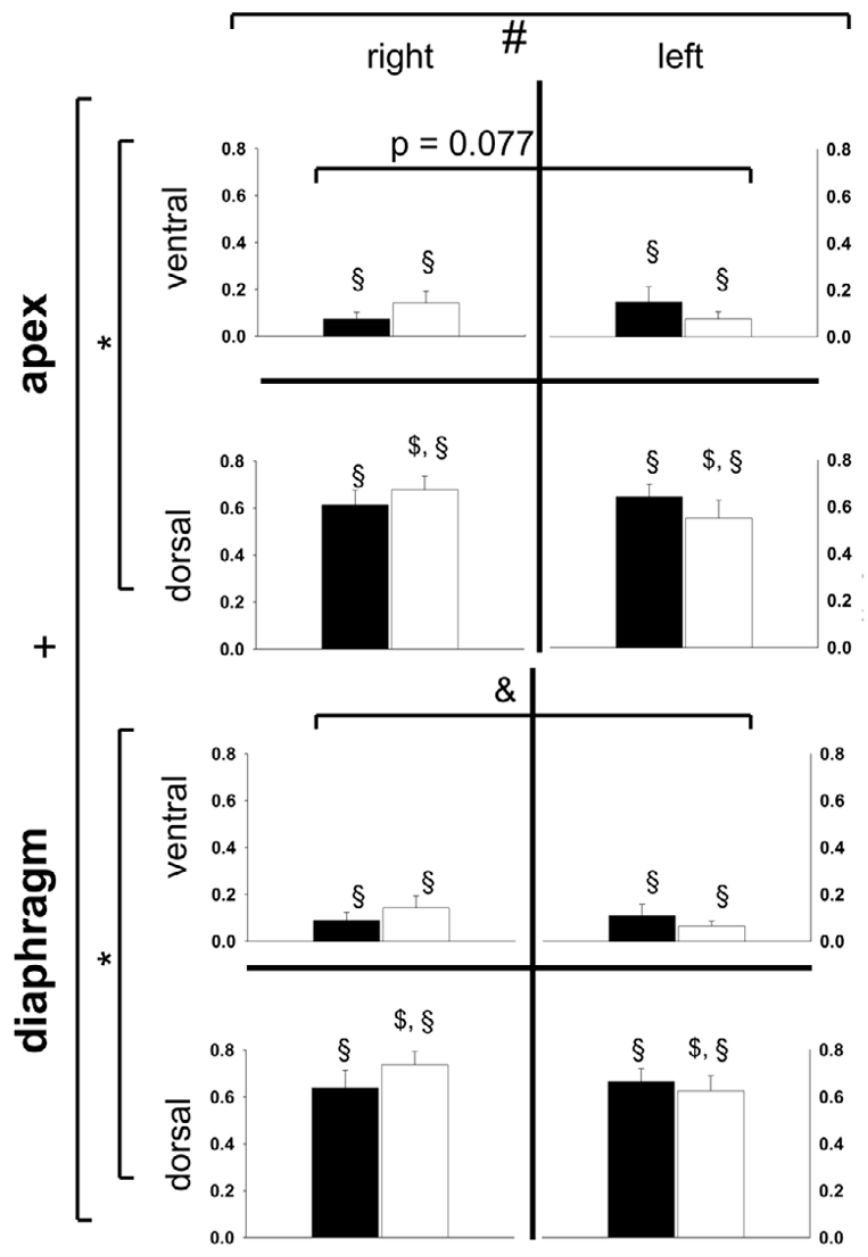

Aerated tissue

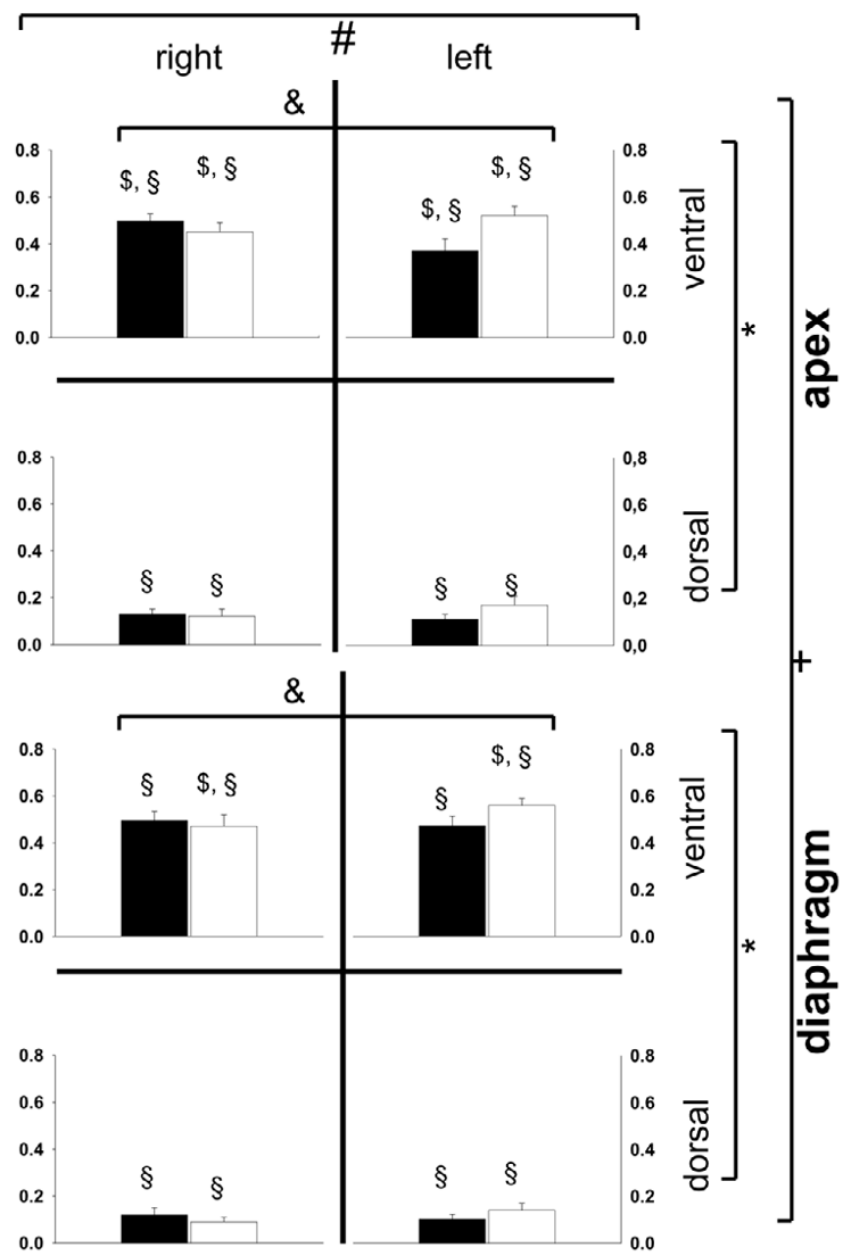

Distribution of fractions of non-aerated and aerated tissue in end-expiratory spiral computed tomography scans. Filled bars indicate oleic acidinduced acute lung injury (ALI), and outlined bars indicate hydrochloric acid-induced ALI. Fractions of densities are presented as mean \pm standard error of the mean. ${ }^{*} P<0.05$ : ventral versus dorsal, analysis of variance (ANOVA). ${ }^{+} P<0.05$ : interaction of ventral-dorsal and apical-diaphragmatic distribution, ANOVA. ${ }^{P} P<0.05$ : interaction injury and left-right distribution. ${ }^{\&} P<0.05$ : left versus right in juxtadiaphragmatic regions for hydrochloric acid-induced ALI, Tukey's honest significant differences (HSD). $\$ P<0.05$ : apex versus diaphragm for corresponding region of interest (ROI), Tukey's HSD. $\$ P<0.05$ : left versus right for corresponding ROI, Tukey's HSD.

oxygenation, but at high $\mathrm{FiO}_{2}$ there will be no substantial effect. High $\mathrm{FiO}_{2}$ will more easily cause collapse (atelectasis) of the low $\dot{V}_{A} / \dot{Q}$ regions. The deterioration in oxygenation in the PCV - SB group can be explained by the reduced blood flow to normal $\dot{V}_{A} / \dot{Q}\left(0.1<\dot{V}_{A} / \dot{Q}<10\right)$ and the concomitant increase in shunt after 4 hours of treatment. The greater dispersion of blood flow $\left(\operatorname{logSD_{\mathrm {Q}}}\right)$ in $\mathrm{HCl}$-induced lung injury after 4 hours of treatment might indicate damage that is more severe [39]. However, this does not translate into a greater deterioration of oxygenation. SB, on the other hand, had no effect on the dispersion of ventilation distribution. Thus, impairments in oxygenation in the PCV - SB group are caused by the increase in shunt. All animals showed a unimodal distribu- tion of perfusion and ventilation, and the residual sum of squares (RSS) was exceptionally low, indicating adequate MIGET data [39].

\section{Effects of spontaneous breathing on hemodynamic parameters}

In contrast to previously published data [10-13,16,36,37], we observed an increase in CO during PCV - SB over the 4-hour treatment period. An animal study found less depression of $\mathrm{CO}$ and oxygen delivery $\left(\mathrm{DO}_{2}\right)$ with $\mathrm{PCV}+\mathrm{SB}$ compared with PCV at similar transpulmonary pressures [40]. In our study, the $\mathrm{CO}$ during $\mathrm{PCV}+\mathrm{SB}$ and $\mathrm{PCV}-\mathrm{SB}$ was comparable to previously published studies $[12,16]$., and the more pronounced increase in the PCV - SB group does not lead to a significant 
Figure 3

$\mathrm{HCl}-\mathrm{ALI}(\mathrm{Oh}, \mathrm{BL})$

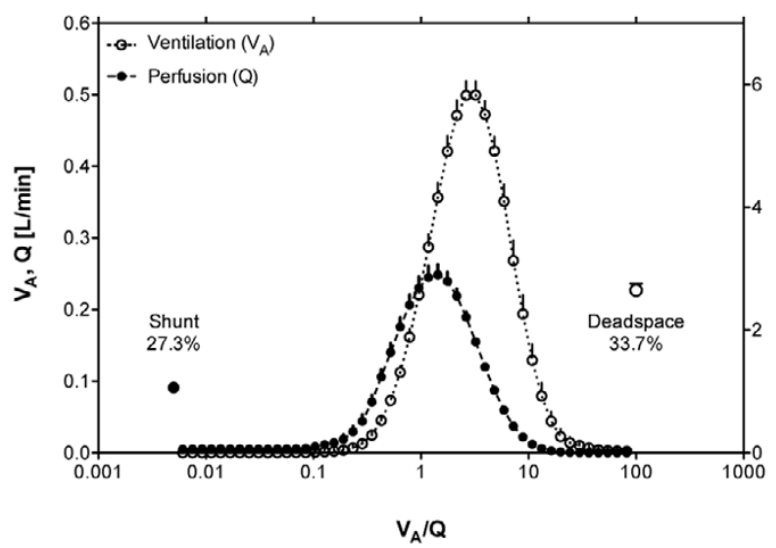

$\mathrm{HCl}-\mathrm{ALI}, \mathrm{PCV}+\mathrm{SB}(4 \mathrm{~h}$, treatment)

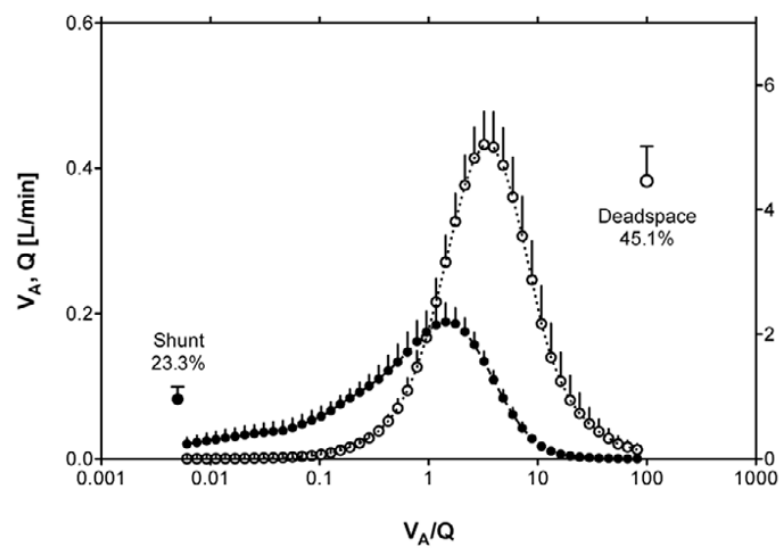

HCl-ALI, PCV - SB (4h, treatment)

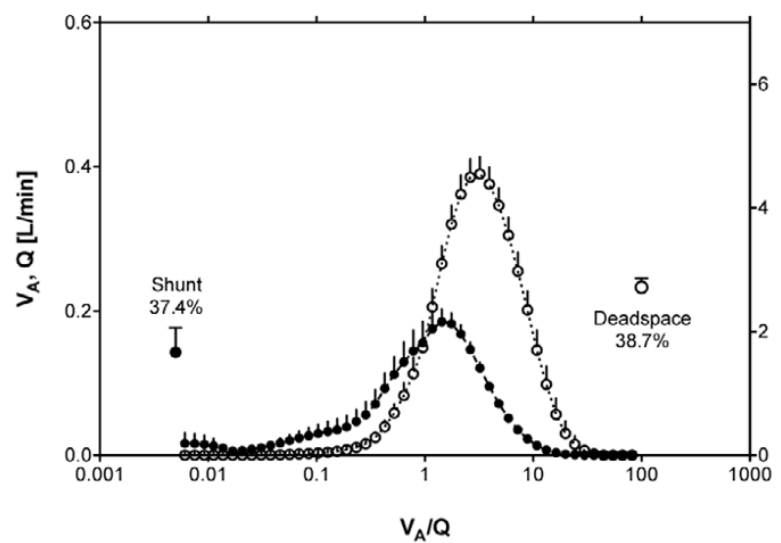

OA-ALI (Oh, BL)

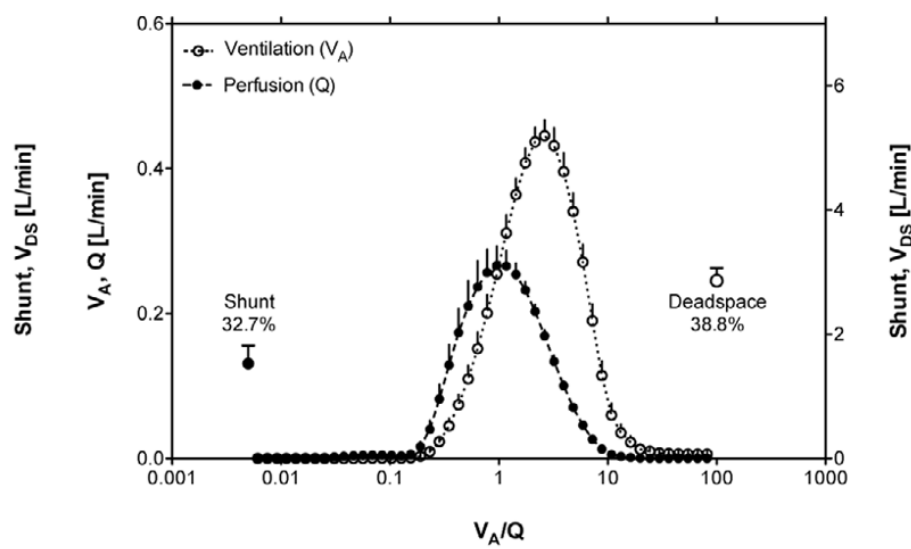

OA-ALI, PCV + SB (4h, treatment)

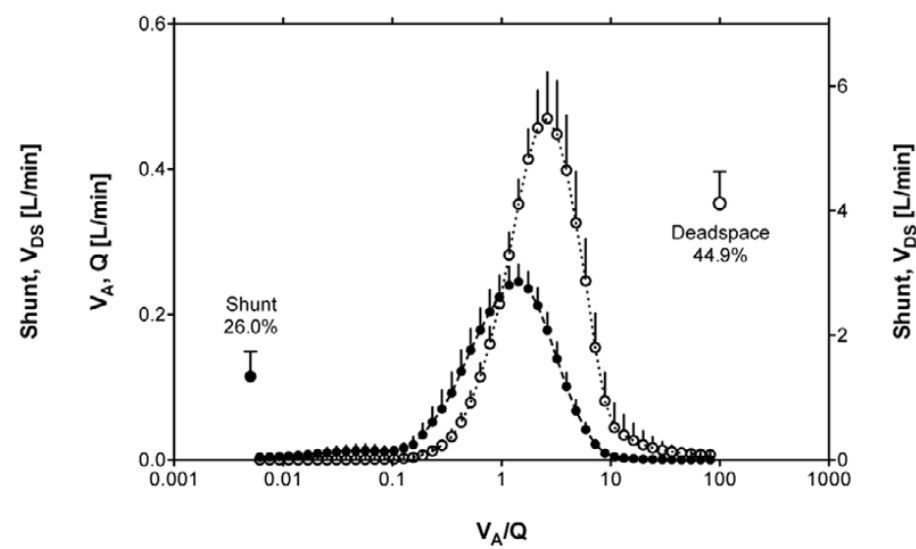

OA-ALI, PCV - SB (4h, treatment)

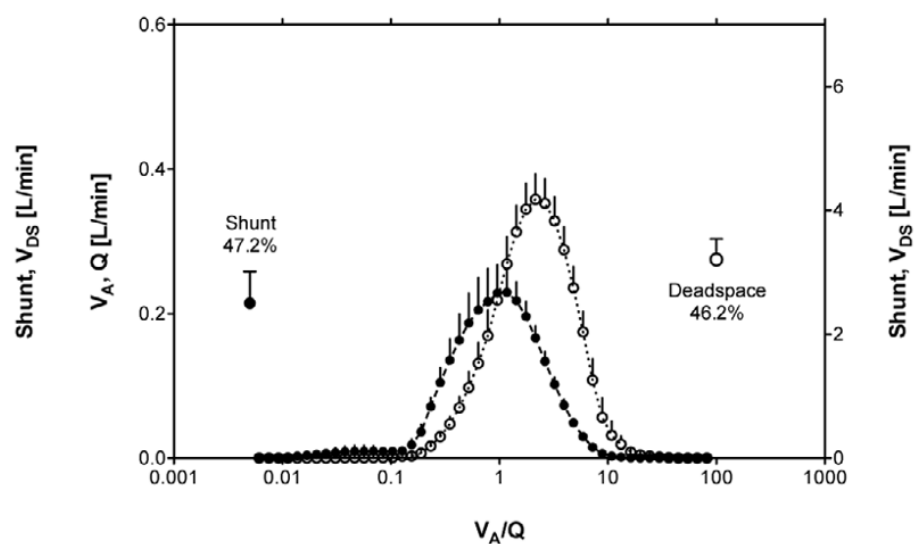

Ventilation/perfusion distributions. Continuous distributions of ventilation and blood flow (mean \pm standard error of the mean) plotted versus ventilation/perfusion ratio $\left(\dot{V}_{A} / \dot{Q}\right)$. BL indicates baseline measurement after induction of stable acute lung injury, and treatment indicates measurement after 4 hours of pressure-controlled ventilation (PCV) either with (+ SB) or without (- SB) spontaneous breathing. HCl-ALI, hydrochloric acidinduced acute lung injury; $\mathrm{OA}-\mathrm{ALI}$, oleic acid-induced acute lung injury; $\mathrm{V}_{\mathrm{DS}}$, deadspace ventilation. 
Figure 4

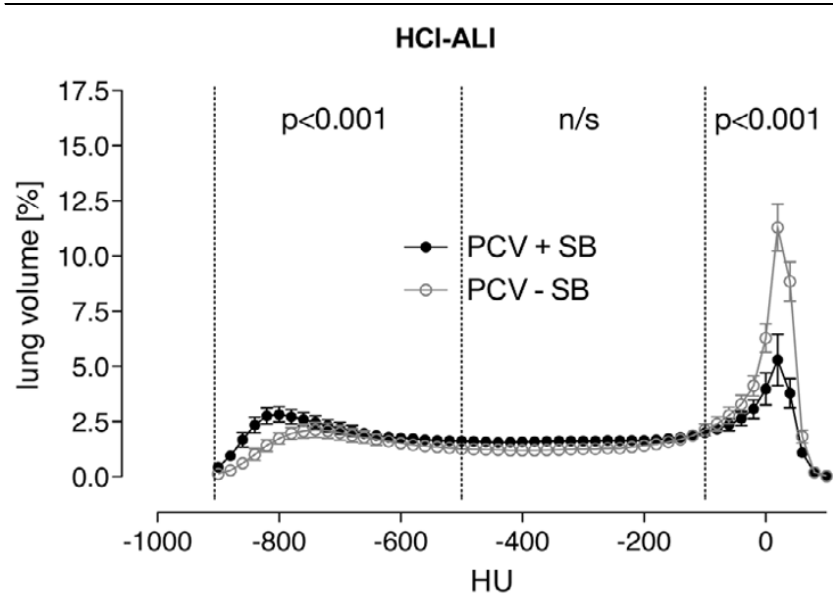

OA-ALI

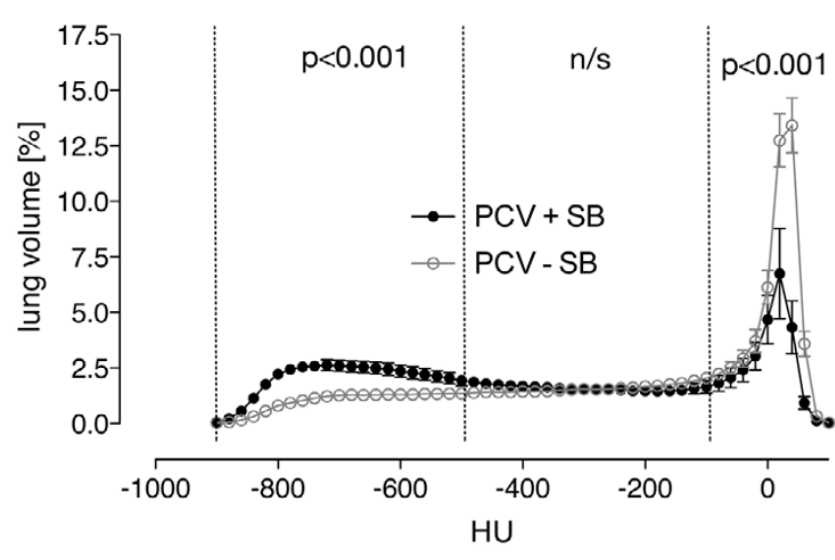

Density distributions. Density histograms taken from end-expiratory spiral computed tomography of all animals show normalized lung volume in Hounsfield units (HU) ranging from $-1,000$ to 100 plotted as mean \pm standard error of the mean. Aeration categories (hyperinflated, normally aerated, poorly aerated, and non-aerated) are marked and were statistically compared (see Results and Discussion sections of the text for details) between pressure-controlled ventilation with $(\mathrm{PCV}+\mathrm{SB})$ and without (PCV - SB) spontaneous breathing. There were no significant differences caused by the type of acute lung injury. $\mathrm{HCl}-\mathrm{ALI}$, hydrochloric acid-induced acute lung injury; $\mathrm{n} / \mathrm{s}$, not significant; OA-A.

increase in $\mathrm{DO}_{2}$. This suggests that the higher $\mathrm{CO}$ was required to maintain an adequate $\mathrm{DO}_{2}$. Linear regression analysis revealed a reasonable inverse correlation between $\mathrm{PaO}_{2} /$ $\mathrm{FiO}_{2}$ and $\mathrm{CO}$ during PCV $+\mathrm{SB}\left(r^{2}=0.42, P<0.05\right)$ after the 4-hour treatment period compared with $r^{2}=0.23(P<0.05)$ in the PCV - SB group. The change in CO is positively correlated with the increase in intrapulmonary shunt $\left(r^{2}=0.36\right)$, which is in line with previously conducted studies [41]. However, as the time frame of our experiments was relatively short, one has to be careful to extrapolate the results on patients with impaired $\mathrm{CO}$ due to, for example, septic cardiomyopathy. The increase in $\mathrm{CO}$ after 4 hours of treatment in the controlled mechanical ventilation group might also be explained by the increased $\mathrm{PaCO}_{2}$ and the lower $\mathrm{pH}$; also, the latter was not statistically significant. In the OA group subjected to controlled mechanical ventilation, the drop in SVR is especially pronounced, which might explain the highest $\mathrm{CO}$ in this group. The ITBV indicates comparable volume status. However, the CVP and the MAP were higher in the indirect ALI group, most likely due to elevated IAP $[7,42,43]$. The mode of ventilation did not influence oxygen consumption $\left(\mathrm{VO}_{2}\right)$, which is in line with previous observations $[10,14]$, whereas $\mathrm{VO}_{2}$ was significantly lower in the OA-induced ALI group, most likely as a consequence of impaired organ perfusion due to increased abdominal pressure.

In this study, we used time-cycled PCV with suppression of SB compared with PCV with maintained SB (also termed airway pressure release ventilation [APRV] or biphasic positive airway pressure [bi-level]). Currently, a number of ventilatory modes supporting SB are available and have been used in animal models of ALI. Noisy pressure support ventilation improved oxygenation and reduced venous admixture at a lower $\mathrm{P}_{\mathrm{aw} \text {, mean }}$ compared with PCV in a model of surfactant depletion [44]. On comparing PCV with different modes of assisted SB (biphasic positive airway pressure, pressure-controlled assisted ventilation, and pressure support ventilation) in a saline lavage animal model, assisted SB was found to be superior to PCV in terms of oxygenation and hemodynamic parameters [45]. The transpulmonary pressure was different in our groups as a result of the increased IAP in the OA group and the comparable PEEP in both groups. Increasing the PEEP to match the groups for transpulmonary pressure could have influenced the results, but this was beyond our scope to investigate the effects of SB. Although several studies reported beneficial effects of $S B$ in $A L I$, we were able to show that PCV with maintained SB has positive effects regardless of the model of $A L I$ used in our study.

\section{Conclusion}

Although the different origin of the ALI results in different respiratory mechanics, EELV, hemodynamic parameters, and shunt fraction, PCV with SB improved oxygenation, reduced shunt fraction, and restored EELV in both types of ALI.

\section{Competing interests}

The authors declare that they have no competing interests.

\section{Authors' contributions}

DV participated in the design and coordination of the study, performed measurements, and wrote the manuscript. TM performed the CT analysis, participated in the study design, and helped draft the manuscript. JZ participated in the design of the study and performed measurements and the statistical analysis. UG analyzed data and helped draft the manuscript. AM participated in the study design and coordination and organized the CT measurements. GH participated in the 


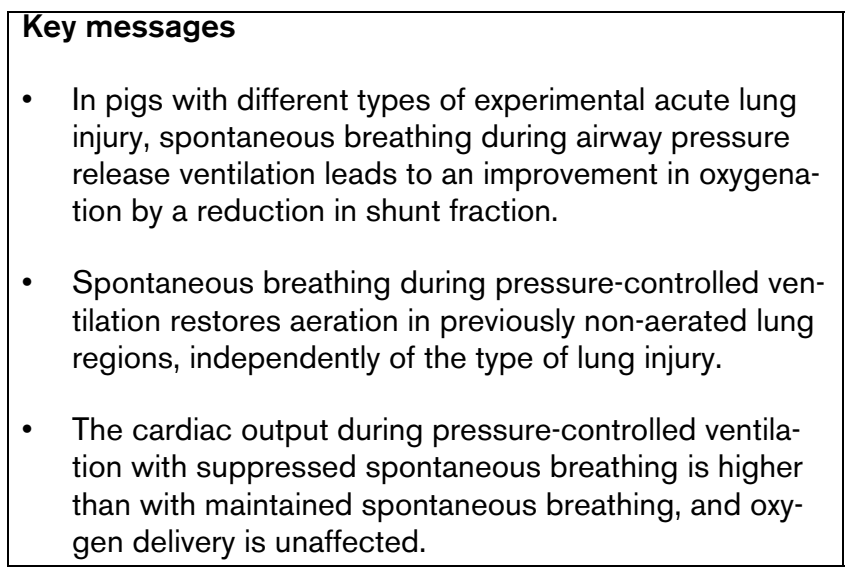

design and coordination of the study and revised the manuscript. CP participated in the design and coordination of the study and helped draft the manuscript. HW designed and coordinated the study, performed measurements, and helped draft the manuscript. All authors edited and approved the final version of the manuscript.

\section{Additional files}

The following Additional files are available online:

\section{Additional data file 1}

A Microsoft Word document giving a detailed description of the methods used for preparation of the animals, determination of ventilation-perfusion ratios, as well as analyses of computed tomography scans.

Furthermore, tables providing additional data on oxygenation, respiratory system mechanics, and hemodynamic parameters are presented in this data file. See http://www.biomedcentral.com/content/ supplementary/cc7108-S1.doc

\section{Acknowledgements}

We thank Eva-Maria Hedin, Anne Abrahamson, and Agneta Roneus, all technicians at the Department of Clinical Physiology, and the x-ray laboratory team (Marianne Almgren, Ann Erikson, and Ewa Larsson, all technicians at the Department of Radiology) of the University of Uppsala, Sweden, for skillful technical help. We are grateful to Marco Strohm, of the Department of Anesthesiology and Surgical Intensive Care, Medical Center Cologne-Merheim, Germany, for his assistance with CT evaluations.

\section{References}

1. Gattinoni L, Pelosi P, Suter PM, Pedoto A, Vercesi P, Lissoni A: Acute respiratory distress syndrome caused by pulmonary and extrapulmonary disease. Different syndromes? Am J Respir Crit Care Med 1998, 158:3-11.

2. Pelosi P, D'Onofrio D, Chiumello D, Paolo S, Chiara G, Capelozzi VL, Barbas CS, Chiaranda M, Gattinoni L: Pulmonary and extrapulmonary acute respiratory distress syndrome are different. Eur Respir J Suppl 2003, 42:48s-56s.
3. Wrigge $\mathrm{H}$, Zinserling J, Muders $\mathrm{T}$, Varelmann $\mathrm{D}$, Gunther U, Groeben C von der, Magnusson A, Hedenstierna G, Putensen C: Electrical impedance tomography compared with thoracic computed tomography during a slow inflation maneuver in experimental models of lung injury. Crit Care Med 2008, 36:903-909

4. Hoelz C, Negri EM, Lichtenfels AJ, Concecao GM, Barbas CS Saldiva PH, Capelozzi VL: Morphometric differences in pulmonary lesions in primary and secondary ARDS. A preliminary study in autopsies. Pathol Res Pract 2001, 197:521-530.

5. Goodman LR, Fumagalli R, Tagliabue $P$, Tagliabue M, Ferrario M, Gattinoni L, Pesenti A: Adult respiratory distress syndrome due to pulmonary and extrapulmonary causes: CT, clinical, and functional correlations. Radiology 1999, 213:545-552.

6. Ranieri VM, Brienza N, Santostasi S, Puntillo F, Mascia L, Vitale N Giuliani R, Memeo V, Bruno F, Fiore T, Brienza A, Slutsky AS: Impairment of lung and chest wall mechanics in patients with acute respiratory distress syndrome: role of abdominal distension. Am J Respir Crit Care Med 1997, 156:1082-1091.

7. Quintel M, Pelosi P, Caironi P, Meinhardt JP, Luecke T, Herrmann P, Taccone P, Rylander C, Valenza F, Carlesso E, Gattinoni L: An increase of abdominal pressure increases pulmonary edema in oleic acid-induced lung injury. Am J Respir Crit Care Med 2004, 169:534-541.

8. Desai SR, Wells AU, Suntharalingam G, Rubens MB, Evans TW, Hansell DM: Acute respiratory distress syndrome caused by pulmonary and extrapulmonary injury: a comparative CT study. Radiology 2001, 218:689-693.

9. Rouby JJ, Puybasset L, Nieszkowska A, Lu Q: Acute respiratory distress syndrome: lessons from computed tomography of the whole lung. Crit Care Med 2003, 31:S285-S295.

10. Sydow M, Burchardi $\mathrm{H}$, Ephraim $\mathrm{E}$, Zielmann $\mathrm{S}$ : Long-term effects of two different ventilatory modes on oxygenation in acute lung injury. Comparison of airway pressure release ventilation and volume-controlled inverse ratio ventilation. Am J Respir Crit Care Med 1994, 149:1550-1556.

11. Putensen $\mathrm{C}$, Zech S, Wrigge $\mathrm{H}$, Zinserling J, Stuber F, von Spiegel T, Mutz N: Long-term effects of spontaneous breathing during ventilatory support in patients with acute lung injury. $A m$ Respir Crit Care Med 2001, 164:43-49.

12. Wrigge $H$, Zinserling J, Neumann $P$, Defosse $J$, Magnusson $A$, Putensen C, Hedenstierna G: Spontaneous breathing improves lung aeration in oleic acid-induced lung injury. Anesthesiology 2003, 99:376-384.

13. Wrigge $H$, Zinserling J, Neumann $P$, Muders $T$, Magnusson $A$, Putensen C, Hedenstierna G: Spontaneous breathing with airway pressure release ventilation favors ventilation in dependent lung regions and counters cyclic alveolar collapse in oleicacid-induced lung injury: a randomized controlled computed tomography trial. Crit Care 2005, 9:R780-R789.

14. Putensen C, Mutz NJ, Putensen-Himmer G, Zinserling J: Spontaneous breathing during ventilatory support improves ventilation- perfusion distributions in patients with acute respiratory distress syndrome. Am J Respir Crit Care Med 1999, 159:1241-1248.

15. Rehder K, Sessler AD, Rodarte JR: Regional intrapulmonary gas distribution in awake and anesthetized-paralyzed man. J Appl Physiol 1977, 42:391-402.

16. Neumann $P$, Wrigge $H$, Zinserling J, Hinz J, Maripuu $E$, Andersson LG, Putensen C, Hedenstierna G: Spontaneous breathing affects the spatial ventilation and perfusion distribution during mechanical ventilatory support. Crit Care Med 2005, 33:1090-1095.

17. Froese $A B$, Bryan $A C$ : Effects of anesthesia and paralysis on diaphragmatic mechanics in man. Anesthesiology 1974, 41:242-255.

18. Reber A, Nylund U, Hedenstierna G: Position and shape of the diaphragm: implications for atelectasis formation. Anaesthesia 1998, 53:1054-1061.

19. Neumann P, Berglund JE, Andersson LG, Maripu E, Magnusson A, Hedenstierna G: Effects of inverse ratio ventilation and positive end-expiratory pressure in oleic acid-induced lung injury. $\mathrm{Am}$ J Respir Crit Care Med 2000, 161:1537-1545.

20. Wagner PD, Saltzman HA, West JB: Measurement of continuous distributions of ventilation-perfusion ratios: theory. $J \mathrm{App} /$ Physiol 1974, 36:588-599. 
21. Wiener-Kronish JP, Albertine $\mathrm{KH}$, Matthay MA: Differential responses of the endothelial and epithelial barriers of the lung in sheep to Escherichia coli endotoxin. J Clin Invest 1991, 88:864-875.

22. Modelska K, Pittet JF, Folkesson HG, Courtney BV, Matthay MA: Acid-induced lung injury. Protective effect of anti-interleukin-8 pretreatment on alveolar epithelial barrier function in rabbits. Am J Respir Crit Care Med 1999, 160:1450-1456.

23. Bitterman PB: Pathogenesis of fibrosis in acute lung injury. Am $J$ Med 1992, 92:39S-43S.

24. Pelosi P: What about primary and secondary ARDS. Minerva Anestesio/ 2000, 66:779-785. discussion 785-786.

25. Julien M, Hoeffel JM, Flick MR: Oleic acid lung injury in sheep. $J$ Appl Physiol 1986, 60:433-440.

26. Kim HY, Lee KS, Kang EH, Suh GY, Kwon OJ, Chung MJ: Acute respiratory distress syndrome. Computed tomography findings and their applications to mechanical ventilation therapy. $J$ Comput Assist Tomogr 2004, 28:686-696.

27. Gattinoni L, Caironi P, Pelosi P, Goodman LR: What has computed tomography taught us about the acute respiratory distress syndrome? Am J Respir Crit Care Med 2001, 164:1701-1711.

28. Pelosi $P$, Cadringher $P$, Bottino N, Panigada M, Carrieri F, Riva E, Lissoni A, Gattinoni L: Sigh in acute respiratory distress syndrome. Am J Respir Crit Care Med 1999, 159:872-880.

29. Riva DR, Oliveira MB, Rzezinski AF, Rangel G, Capelozzi VL, Zin WA, Morales MM, Pelosi P, Rocco PR: Recruitment maneuver in pulmonary and extrapulmonary experimental acute lung injury. Crit Care Med 2008, 36:1900-1908.

30. Gattinoni L, Caironi $P$, Cressoni M, Chiumello D, Ranieri VM, Quintel M, Russo S, Patroniti N, Cornejo R, Bugedo G: Lung recruitment in patients with the acute respiratory distress syndrome. N Engl J Med 2006, 354:1775-1786.

31. Thille AW, Richard JC, Maggiore SM, Ranieri VM, Brochard L: Alveolar recruitment in pulmonary and extrapulmonary acute respiratory distress syndrome: comparison using pressurevolume curve or static compliance. Anesthesiology 2007, 106:212-217.

32. Rubenfeld GD, Herridge MS: Epidemiology and outcomes of acute lung injury. Chest 2007, 131:554-562.

33. Dellinger RP, Jean S, Cinel I, Tay C, Rajanala S, Glickman YA, Parrillo JE: Regional distribution of acoustic-based lung vibration as a function of mechanical ventilation mode. Crit Care 2007, 11:R26.

34. Andersson LE, Baath M, Thorne A, Aspelin P, Odeberg-Wernerman S: Effect of carbon dioxide pneumoperitoneum on development of atelectasis during anesthesia, examined by spiral computed tomography. Anesthesiology 2005, 102:293-299.

35. Puybasset L, Cluzel P, Chao N, Slutsky AS, Coriat P, Rouby JJ: A computed tomography scan assessment of regional lung volume in acute lung injury. The CT Scan ARDS Study Group. Am J Respir Crit Care Med 1998, 158:1644-1655.

36. Putensen C, Rasanen J, Lopez FA, Downs JB: Effect of interfacing between spontaneous breathing and mechanical cycles on the ventilation-perfusion distribution in canine lung injury. Anesthesiology 1994, 81:921-930.

37. Putensen C, Rasanen J, Lopez FA: Ventilation-perfusion distributions during mechanical ventilation with superimposed spontaneous breathing in canine lung injury. $A m J$ Respir Crit Care Med 1994, 150:101-108

38. Dantzker DR, Brook CJ, Dehart P, Lynch JP: Ventilation-perfusion distributions in the adult respiratory distress syndrome. $A m$ Rev Respir Dis 1979, 120:1039-1052.

39. Roca J, Wagner PD: Contribution of multiple inert gas elimination technique to pulmonary medicine. 1 . Principles and information content of the multiple inert gas elimination technique. Thorax 1994, 49:815-824.

40. Henzler D, Dembinski R, Bensberg R, Hochhausen N, Rossaint R, Kuhlen R: Ventilation with biphasic positive airway pressure in experimental lung injury. Influence of transpulmonary pressure on gas exchange and haemodynamics. Intensive Care Med 2004, 30:935-943.

41. Lynch JP, Mhyre JG, Dantzker DR: Influence of cardiac output on intrapulmonary shunt. J App/ Physio/ 1979, 46:315-321.

42. O'Mara MS, Papasavas PK, Newton ED, Caushaj PF: Modified separation of parts as an intervention for intraabdominal hypertension and the abdominal compartment syndrome in a swine model. Plast Reconstr Surg 2004, 114:1842-1845.

43. Rosenthal RJ, Friedman RL, Chidambaram A, Khan AM, Martz J, Shi Q, Nussbaum M: Effects of hyperventilation and hypoventilation on $\mathrm{PaCO}_{2}$ and intracranial pressure during acute elevations of intraabdominal pressure with $\mathrm{CO}_{2}$ pneumoperitoneum: large animal observations. J Am Coll Surg 1998, 187:32-38

44. Gama de Abreu M, Spieth PM, Pelosi P, Carvalho AR, Walter C, Schreiber-Ferstl A, Aikele P, Neykova B, Hubler M, Koch T: Noisy pressure support ventilation: a pilot study on a new assisted ventilation mode in experimental lung injury. Crit Care Med 2008, 36:818-827.

45. Henzler D, Pelosi P, Bensberg R, Dembinski R, Quintel M, Pielen $V$, Rossaint $R$, Kuhlen R: Effects of partial ventilatory support modalities on respiratory function in severe hypoxemic lung injury. Crit Care Med 2006, 34:1738-1745.

46. Baydur A, Behrakis PK, Zin WA, Jaeger M, Milic Emili J: A simple method for assessing the validity of the esophageal balloon technique. Am Rev Respir Dis 1982, 126:788-791.

47. Higgs BD, Behrakis PK, Bevan DR, Milic-Emili J: Measurement of pleural pressure with esophageal balloon in anesthetized humans. Anesthesiology 1983, 59:340-343.

48. Brunner JX, Wolff G: Pulmonary Function Indices in Critical Care Patients Heidelberg, Germany: Springer-Verlag; 1988.

49. Iberti TJ, Lieber CE, Benjamin E: Determination of intra-abdominal pressure using a transurethral bladder catheter: clinical validation of the technique. Anesthesiology 1989, 70:47-50.

50. Gattinoni L, Pesenti A, Bombino M, Baglioni S, Rivolta M, Rossi F, Rossi G, Fumagalli R, Marcolin R, Mascheroni D, Torresin A: Relationships between lung computed tomographic density, gas exchange, and PEEP in acute respiratory failure. Anesthesio/ogy 1988, 69:824-832.

51. Lundquist $H$, Hedenstierna $G$, Strandberg A, Tokics L, Brismar $B$ CT-assessment of dependent lung densities in man during general anaesthesia. Acta Radiol 1995, 36:626-632.

52. Vieira SR, Puybasset L, Richecoeur J, Lu Q, Cluzel P, Gusman PB Coriat $P$, Rouby JJ: A lung computed tomographic assessment of positive end-expiratory pressure-induced lung overdistension. Am J Respir Crit Care Med 1998, 158:1571-1577

53. Drummond GB: Computed tomography and pulmonary measurements. Br J Anaesth 1998, 80:665-671. 